\title{
Death Diagnosis Result Category
}

National Cancer Institute

\section{Source}

National Cancer Institute. Death Diagnosis Result Category. NCI Thesaurus. Code C102742.

A classification of a death diagnosis result. 